\title{
Recovery of Pathogenic Human Intestinal Parasites in Fecal Effluents Obtained from Donkey Abattoir at Nkwo-Izhia, Ebonyi State
}

\author{
Agumah Nnabuife Bernard, ${ }^{1,}$, Nwakaeze Emmanuel Amobi ${ }^{1}$, Nwachi Anthonia Chinyere ${ }^{1}$, \\ Ilang Donatus Chukwuma ${ }^{2}$, Ebiega-Oselebe Ifeoma Nora ${ }^{3}$, Iyidiobi Tochukwu Chiaghanam ${ }^{4}$, \\ Dzingina Garba Douglas ${ }^{5}$, Uhuo Cosmas ${ }^{6}$
}

${ }^{1}$ Department of Applied Microbiology, Ebonyi State University, Abakaliki, Nigeria

${ }^{2}$ Department of Biological Sciences, Federal University, Ndufu-alike Ikwo, Nigeria

${ }^{3}$ Department of Epidemiology and Medical statistics, University of Ibadan, Ibadan, Nigeria

${ }^{4}$ Department of Internal medicine, Federal teaching hospital, Abakaliki, Nigeria

${ }^{5}$ School of Medical laboratory Sciences, Ahmadu Bello University, Zaria, Nigeria

${ }^{6}$ Department of Applied biology, Faculty of Science, Ebonyi state University, Abakaliki, Nigeria

\section{Email address:}

buifewenemighty@gmail.com (A. N. Bernard)

\section{To cite this article:}

Agumah Nnabuife Bernard, Nwakaeze Emmanuel Amobi, Nwachi Anthonia Chinyere, Ilang Donatus Chukwuma, Ebiega-Oselebe Ifeoma Nora, Iyidiobi Tochukwu Chiaghanam, Dzingina Garba Douglas, Uhuo Cosmas. Recovery of Pathogenic Human Intestinal Parasites in Fecal Effluents Obtained from Donkey Abattoir at Nkwo-Izhia, Ebonyi State. American Journal of Biomedical and Life Sciences.

Vol. 3, No. 3, 2015, pp. 71-74. doi: 10.11648/j.ajbls.20150304.11

\begin{abstract}
Donkey meat is a delicacy in some cultures even though it is abhorred in some quarters; and because it is relatively cheaper, tastier and nutritionally-rich, donkey meat is preferred to some other types of red especially in this part of the world. Donkeys are usually imported from the Northern part of Nigeria to some parts of the South where people buy them for consumption and other economic purposes. This study was aimed at recovering pathogenic human intestinal parasites from donkeys to ascertain if they could be potential reservoirs of human parasites. The fecal effluents from the donkey abattoir were analyzed based on current parasitological techniques; and the parasites were confirmed by microscopic and concentration techniques. Twenty-five (79.5\%) species of helminths and $9(20.5 \%)$ species of protozoa were identified in the donkeys slurry samples examined in this study. This gives a general parasite prevalence of $55.0 \%(44 / 80)$. These comprised of 16 (36.4\%) Fasciola hepatica; 10 (22.8\%) Taenia spp; 7 (15.9\%) Giardia lamblia; 3 (6.8\%) Ascaris lumbricoides; 3 (6.8\%) Strongyloides stercolaris; 2 (4.5\%) Trichuris trichuria; 2(4.5\%) Entamoeba histolytica and 1 (2.3\%) hookworm. One animal each harbored 3 species, 17 animals had two separate parasitic infections and 26 harbored one parasitic species. It could be deduced from our results that parasitic infections are not duly considered in veterinary control especially in slaughter houses as possible causes or source of infections. Thus, parasitic control and protective actions will be necessary in order to utilize donkeys more efficiently as well as to contain the spread of infections via their consumption.
\end{abstract}

Keywords: Parasites, Donkey, Abattoir, Fecal, Effluents, Ebonyi

\section{Introduction}

Donkeys (Equus asinus) are among the early-domesticated equines that have been around as long as mankind; and they serve a variety of economic importance to mankind (Saul et al., 1997; Alemu et al., 2004; Abayneh et al., 2002). In some area of North West Kenya and Southern Ethiopia, donkey meat is a delicacy and the milk is believed to treat whooping cough (Fred and Pascal, 2006; Pearson et al, 2009). Donkeys are prone to a number of infectious and non-infectious diseases; and they harbour parasites such as Strongyles, Ascarids, pin worms, Gastrophilus, lung worms, fluke and tape worms amongst others. Even though donkeys have often been described as study animals, they succumb to a variety of diseases and a number of other conditions (Svendsen, 2007).

Parasitic helminthes are one of the most common factors that constrain the health and working performance of 
donkeys and horses worldwide. They cause various degrees of damage depending on the species and number at present, nutritional and the immune status of eqiuds (Asefa et al., 2011). They decrease the performance, production and productivity in the animals mainly in the reduction of body weight or failure to gain weight or even increase the mortality in acute case (Ramaswamy, 1994). A number of studies con- ducted to detect association between poverty and animal diseases identified gastrointestinal parasitism as one of the most important problems for eqiuds in developingcountries (Perry et al., 2002; Valdez-Cruz et al., 2006).

The prevalence and type of internal parasites affecting eqiuds, in general, are ubiquitous with equines being continually exposed throughout their lives. The attention given by Governmental and non-Governmental organizations to donkeys has been far below to what it deserves. This might be partly due to the wrong perception that the donkey does not require a lot of care, that when donkeys do get sick they are quick to die, and the donkey's low traditional status (Marshall and Ali, 2004). The attention given by donkey owners to their animals is below the level that it should be. This might be partly due to the incorrect perception that donkeys do not require a lot of care, but it can be concluded that the elimination of their parasites would improve the adaptation of the animals to the harsh dry season and also the cold winter in most regions of Nigeria.Butchers as well as individuals who purchase donkey meat for consumption are prone to risks of being infected with these pathogenic intestinal parasites especially when hygiene practice is low. Effluents that result from the abattoir harbor potentially pathogenic parasites. Some of these parasites have inherent mechanisms that enable them to penetrate intact skin while the others gain entrance through the ingestion of infected and poorly cooked donkey meat. This study evaluated the incidence of pathogenic human intestinal parasites in feacal effluents obtained from donkey abattoir in Abakaliki, Ebonyi state.

\section{Materials and Methodology}

Study Area: The study area is Ohaukwu local government area in Ebonyi State, South Eastern part of Nigeria. It has an area of $517 \mathrm{~km}^{2}$ and a population of 196,337 at the 2006 census (The world-Gazetteer, 2007). Ebonyi State is located at $6^{\circ} 15^{\prime}$ north of the equator and longitudes $8^{\circ} 05^{\prime}$ east of the meridian. This location confers on the state the equatorial climatic conditions. There are two distinct seasons namely wet and dry seasons. The wet season is the period for rainfall, which is between mid-April and October. The dry season lasts between November and March. The rainfall pattern is remarkably constant ranging between $1,211 \mathrm{~mm}$ and the mean temperature is $33^{\circ} \mathrm{C}$. Rice and roots crops like yam are the main agricultural products.

Sample Collection: Donkey slurries were randomly collected from the donkey abattoir at Nkwo-Izhia in Ohaukwu Local Government Area in Ebonyi State. A total of
320 samples were collected and used in this study. The samples were aseptically collected and analyzed at the Applied Microbiology and Parasitological laboratory, Faculty of Sciences Complex, Ebonyi State University, Abakaliki. All samples were collected in clean transparent wide mouth, screw capped universal container for laboratory processing. And the slurry samples collected were properly numbered, labeled and transported to the laboratory for parasitological investigations.

Concentration techniques: All Slurry samples collected were analysed using the Formol ether concentration technique (Cheesbrough, 2006; Ochei and Kolhatkar, 2007).

\section{Result}

Table 1 shows the prevalence of parasites in the study population included in this current study.Most of the slurries examined were found to harbour gastrointestinal parasites. The infection status prevalence in donkeys is shown in Table 2. A general incidence rate of $55 \%$ was recorded with over 176 slurry samples out of 320 .

Seventy five percent $(79.5 \%)$ of parasites discovered were helminthes while 20.5\% were Protozoan parasites.

Parasites recovered includeFasciola spp (36.4\%) Taenia spp (22.8\%), Giardia lamblia (15.9\%), Ascaris spp (6.8\%), Strongyloides spp (6.8\%), Trichuris trichuria (4.5\%), Entamoeba histolytica (4.5\%) and Hookworms (2.3\%).

Figure 1 shows the percentage of protozoa and helminthsin the isolated parasites.

Table 1. Prevalence of Parasites in the Study Population.

\begin{tabular}{lll}
\hline Parasite & No recovered & Prevalence (\%) \\
\hline Fasciola hepatica & 64 & 36.4 \\
Taenia spp & 40 & 22.8 \\
Giardia lamblia & 28 & 15.9 \\
Ascaris spp & 12 & 6.8 \\
Strongyloides Spp & 12 & 6.8 \\
Trichuris trichuria & 8 & 4.5 \\
Entamoeba histolytica & 8 & 4.5 \\
Hookworm & 4 & 2.3 \\
Total & 176 & 100 \\
\hline
\end{tabular}

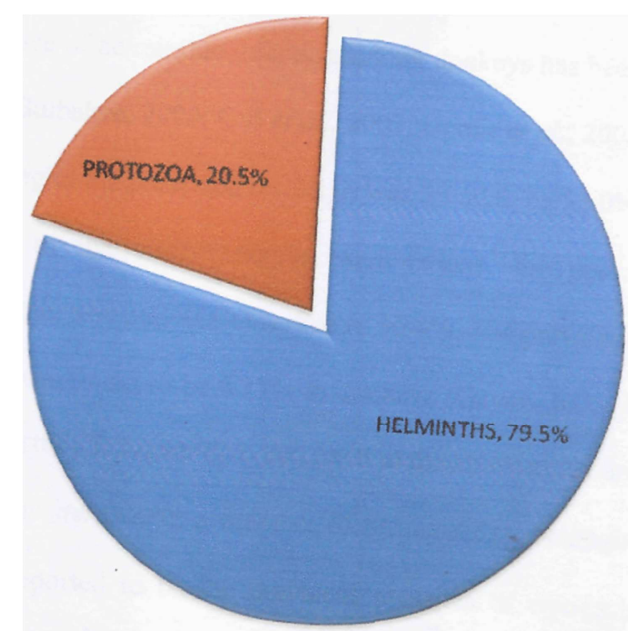

Figure 1. percentage of protozoa and helminthes in the isolated parasite. 
Table 2. Infection Status Prevalence in Donkeys.

\begin{tabular}{lll}
\hline Infection status & No of Infected Sample & Prevalence (\%) \\
\hline Total & 44 & 55.0 \\
\hline
\end{tabular}

\section{Discussion}

The incidence of helminthic infection among donkeys has been reported from other studies with values ranging from 77.3\%-100\% (Gulbahce, 2000; Gul et al., 2003; Demir et al., 2005; Arslan and Umur, 2008). Though this study reported a lesser incidence $(55 \%)$, it is relatively assumed to be line in with previous studies.From this study, the incidence ofFasciola spp, a helminthic parasite, was observed as $36.4 \%$. The prevalence of Fasciola sp. in the Konya region was found to be $6.17 \%$ in donkeys (Gavor, 2005; Demir et al., 2005). These two findings do not tally as the incidence of this trematode was higher from this study. Strongyloides stercolaris, a member of Strongylidae, belonging to the nematode family, has been reported to be the prevalent parasites of equids (Arslan and Umur. 2008). Examination of feacal by-product of donkey reported in other studies presented incidence rates ranging from $72.7-100 \%$, which is quite higher than the $6.8 \%$ rate reported in our study (Gul et al., 2003; Demir et al., 2005; Arslan and Umur, 2008).The disparity in prevalence's could be due to the different geographical regions of origin of these donkeys and number of slurry samples examined.Demir et al., 2005 and Arslan and Umur, 2008 reported incidence of T. trichuria as 1.2\% and $1.3 \%$ respectively and their findings were lesser as compared with this study(4.5\%).The incidence of Faciola sppand Taenia spp. in this study could be a possible indication that donkeys are potential reservoirs for Fascioliasis and Taeniasis which are two of the most important and prevalent species of nematodes in ruminants. Fascioliasis is also prevalent in humans in Nigeria (Moghadam, 2004).In general, in Ebonyi State, as in many other parts of the world, the attention given by donkey owners to their animals is below the level that it should be. This might be partly due to the incorrect perception that donkeys do not require a lot of care, but it can be concluded that the elimination of their parasites would improve the adaptation of the animals to the harsh dry season and also the cold winter in most regions of Nigeria. Records from this study can still be attributed to other factors like: physical distribution, the general health and nutrition of these animals and the condition under which the animals are kept.The effective inspection of donkeys for consumption purposes is critical as this will halt the transmission of pathogenic parasites to humans through consumption. Adequate veterinary care should be maintained especially as regards the deworming of these animals. Donkey abattoirs should be properly sanitized and feacal effluents from such slaughter houses should be properly disposed or channeled so that they do not contaminate the sources of drinking water for people living in the environs where these animals are kept or slaughtered.

\section{References}

[1] Abayneh, T., Gebreab, F., Zekarias, B. and Tadesse, G. (2002). The potential role of donkeys in land tillage in central Ethiopia. Bulletin of Animal Health and Production in Africa. 50, 172-178.

[2] Arslan, M.O. and Umur, S. (2008). The helminth and Eimeria (Protozoa) species in horse and donkey in Kars. Acta Parasitol Turcica; 22:80-184.

[3] Asefa Z., Kumsa B., Endebu B., Gizachew A., Merga T. and E. Debela E., (2011) "Endoparasites of Donkeys in Sululta and Gefersa Districts of Central Oromia, Ethiopia," Journal of Animal and Veterinary Advances. 10(14)1850-1854.

[4] Demir, S., Tinar, R. and Kaplan, A. (2005). Helminths obtained from a donkey. Acta Parasitol Turcica; 19:119-123.

[5] Fred, O. and K, Pascal, 2006. Extension approaches toimproving the welfare of working equines. Kenya from eastern Uganda. Paper presented at the international Animal Traction Network for Eastern and Southern Africa (ATNE3A) workshop held 5-9 May 1997. Debre Zeit, Ethiopia, Website: http://www.atnesa.org/atnesa-donkey- workshop

[6] Gavor, J. J. (2005). The prevalence and abundance of internal parasites in working horses autopsied in Poland. Vet Parasitol; 58:99-108.

[7] Gul, A., Deger, S. and Ayaz, E. (2003). The prevalence of helminth species according to faecal examination in equids in different cities in Turkey. Turk J Vet AnimSet; 27:195-199.

[8] Gulbahce, S. (2000). Epidemiology of parasites found in equids in province Konya. Selcuk Univ., Might Lisans Thesis. Health Science Enstitusu; pp23-43.

[9] Marshall, K. and Ali, Z, (2004), In; Fielding and Starkey P (editors). Donkeys, People and Development. A resource book of the animal traction network for eastern and Southern Africa (ATNESA). Technical center for agriculture and rural cooperation (CTA), Wageningen, The Netherlands, pp. 77-81.

[10] Moghadam, A.S., Massoud, ],, Mahmoodi, M., Mahvi, A.H., Periago, M.V. and Artigas, P. (2004). Human and animal fasciolosis in Mazandaran province, Northern Iran. Parasitol. Res', 94:61-69.

[11] Pearson, R. A, Nengomasha, E. and Krecek, R. C. (2009). The challenges in using donkeys for work in Africa. In: Starkey $\mathrm{PH}$, Kaumbutho P (editors). Meeting the Challenges of Animal Traction. A resource book of the Animal Traction Network for Eastern and Southern Africa (ATNESA), pp, 190198, Harare, Zimbabwe. Intermediate Technology Publications, London.Uk,

[12] Perry B. D., Randolph T. F., McDermott J. J., Sones K. R. and Thornton P. K., (2002) "Investing in Animal Research to Alleviate Poverty,” International Livestock Research Institute, Nairobi.

[13] Poynter, D. (2000) Some observations on the nematode parasites of horses. In: Bryans J T, Gerber H (editors), Equine Infectious Diseases. Proceedings 2nd International Conference on Equine Infectious Diseases, Paris, (Basel, Switzerland, S.Karger), Pp. 269-289. 
[14] Ramaswamy R. S.,(1994) "Draught Animals and Welfare," Re-vue Scientifique et Technique de l'Office International des Epizooties, Vol. 13(1): 195-216.

[15] Saul, C., Siefert, L. and Gpuda-Asibo, J. (2007). Disease and Health problems of donkeys: a case study from eastern Uganda. In: Improving donkey utilization and management. ATNESA workshop, 5-9, Debre Zeit, Ethiopia. Pp58-63.

[16] Svendsen, E.D., (2007). Parasites abroad. The professional hand book of the donkey. 3 edition pp: 166-182, Whittet Books Limited, 18 Anley Road, London, pp: 166-182.
[17] Valdez-Cruz, P. Z., Hernandez-Gil M., Galindo-Rodriguez L. and Alonso-Diza M. A.,(2006) "Gastrointestinal Parasite Burden, Body Condition and Haematological Values in Equines in the Humid Tropical Areas of Mexico," Proceedings of the 5th International Colloquium on Working Equines The Future for Working Equines, The Donkey Sanctuary, Sidmouth. pp. 62-72. 